\title{
Assessing speech and communication impairments in cognitive disorders: an innovative development in a memory clinic
}

\author{
"Last scene of all, That ends this strange eventful \\ history, \\ Is second childishness and mere oblivion, \\ Sans teeth, sans eyes, sans taste, sans everything"
}

(Shakespeare, As You Like It)

\section{Introduction}

Although there is a great emphasis on memory in the diagnosis of dementia and in the measurement of treatment response, disorders of language are an important, but sometimes neglected, feature of many dementias.

In 2005 the Academic Unit for the Psychiatry of Old Age of the University of Melbourne was located at St. George's Hospital in the inner eastern suburbs of Melbourne, Australia. In association with the Unit's Memory and Related Disorders Clinic (MRDC), the Inner East Community Health Service (IECHS) established a Speech and Communication Clinic (SCC). The purpose of the collaboration was to provide an innovative service to the older members of the community.

The SCC was initiated following another joint project (Goh et al., 2008), a training program for commercial service providers who deal with elderly citizens in the suburban community of Boroondara, a local government administrative area in the inner eastern suburbs of Melbourne. It is one of the oldest established municipalities in the Melbourne metropolitan area. It houses a predominantly professional class, has the fourth highest mean income (Australian Taxation Office, 2006-7), has 27,000 people aged over 60 years, or $16 \%$ of its population, and the largest number of residents over 85 years in the state of Victoria. The program provided education to representatives of agencies with the aim of improving practices and attitudes to their aging clientele. A set of ten principles were subsequently documented in a Charter and made available to all participants and presented to the municipal council.

\section{The Memory and Related Disorders Clinic}

The Memory and Related Disorders Clinic (MRDC) provides assessment, management, mon-

First published online 9 October 2009. itoring, review and education for its patients. Social supports are also brokered as needed. The clinic works in collaboration with its referral sources, general practitioners (GPs), mental health agencies, community health services, and the residential care sector. Referrals include a mix of aged patients presenting with primary degenerative dementias, mild cognitive impairment and subjective memory complaints. Patients requiring differential diagnosis for cognitive disorders of uncertain etiology include those with head injury, vascular changes without dementia, stroke, alcohol abuse, hydrocephalus, frontal lobe disorders, white-matter abnormalities, anxiety, depression, and post respiratory infection delirium.

Referring practitioners receive timely and sequential written reports and there is an open opportunity for GP- and patient-initiated telephone consultation and support. The entire program is based on accessible service provision and clinical research within the multidisciplinary setting of an academic unit.

\section{The Speech and Communication Clinic}

The Speech and Communication Clinic operates weekly in collaboration with the MRDC and patients are routinely offered a speech and language assessment as part of the service.

The assessment includes a screen of psycholinguistic abilities, visual perception and an estimate of pre-morbid verbal intelligence using the New Adult Reading Test (NART; based on Nelson and O'Connell, 1978). A speech sample is recorded; a description of a cartoon with six frames, and a 90-second monologue of the patient's history. The cartoon and discourse tasks are measured for word fluency (the words spoken in the given time) and coherence through cohesion, or how well their speech "hangs together", after the methodology described by Hasan (1984).

\section{Language disorders and psychiatry}

Language dysfunction has always been associated with psychiatric conditions, as argued, for example, 
in the stimulating genetics paper by Crow (1977), "Is schizophrenia the price that Homo sapiens pays for language". Certainly, speech disorder has been integral to the nature and diagnosis of schizophrenia. Both Kraepelin and Bleuler considered abnormalities of communication or thinking to be fundamental to schizophrenia and accounts of thought disorder are dominated by communication impairment.

In 1979 Andreasen described thought disorder in terms of verbal language disturbance, generalizing it to psychiatric conditions including mania and depression (Andreasen, 1979). Morice and Ingram (1982), and later Thomas and Fraser (1994) and Thomas (1997), examined the grammatical structure and language in the dialectics of schizophrenia. This was developed further by Thompson and Copolov (1998) who assessed hallucinating and non-hallucinating schizophrenia with both cognitive and psycholinguistic probes, and also by analyzing speech samples. While the language probes separated healthy controls from both psychiatric groups, they did not differentiate the two pathologies. However, the discourse scores did provide this differentiation, which raised the tantalizing thought that language analysis of everyday speech samples could be a diagnostic tool in heterogeneous neuro-psychiatric disorders.

Williamson et al. (1964) first described the unreported service needs of elderly people with dementia in Scotland and called the prevalence a "silent epidemic". In the same year, the eminent English neurologist Macdonald Critchley (1964) was uncertain what to call this language of dementia, preferring "dyslogia", since "dysphasia" was a language disorder resulting from circumscribed cerebral lesions. Twenty years later British speech therapists were taking an interest in the language of aging people. Two studies confirmed that there was a difference, by factor analysis, of the language of dementia and dysphasia and this, of course, meant that traditional aphasia tests had neither face nor content validity to measure language in dementia (Stevens, 1985; Thompson, 1986). Another pair of coincidental studies (Walker, 1982; Thompson, 1986) demonstrated that $14 \%$ of normal aging people will make language errors similar to those with mild cognitive impairment. It took another twenty years before the National Institute of Health and Clinical Excellence (NICE) in the U.K., when evaluating pharmacological treatments for dementia, stated that the MMSE (Folstein et al., 1975), which is used to determine cognitive impairment, was not appropriate for use with those who are language disordered (NICE, 2006).
Thompson (1986; 1987) investigated two large populations with aphasia or dementia. He confirmed that "aphasia" was not an appropriate description of the language of people with dementia, that language pathology differs according to the diseases that cause it, and that some, not all, language abilities deteriorate in degenerative cerebral disease. He identified a set trend in the deterioration of language variables over three years in a group of non-medicated people diagnosed with Alzheimer's disease. His current research in the Speech and Communication Clinic uses a psycholinguistic investigation and is exploring the possibility that the patients taking cholinesterase inhibitors may have retained processing skills. This poses three possible hypotheses: (i) psycholinguistic constructs may be different from the neurology of language; (ii) pre-morbid verbal intelligence may help people to communicate better than their dementia would suggest; and (iii) cholinesterase inhibitors may enhance linguistic processing.

The lack of research into the understanding of language impairment in dementia (and psychiatry in general) has left gaps in service delivery. First, there exists an available, but as required, referralbased assessment service for people with dementia and their carers. Of the 11 publicly funded memory clinics in Melbourne, three have only part-time speech pathologists. Second, most speech clinicians have little knowledge of language impairment in dementia and give limited advice to aged-care workers, patients and carers. It is the carers who bear the burden of not being able to converse and understand the needs of people for whom they may have a lonely and unsupported long-term responsibility.

\section{Assessment of the language of dementia}

Language is different as a higher cortical function, or as a cognitive activity, or as a means of communication in everyday life. Localized cortical damage will produce specific dysphasias in speaking or understanding language. People with Alzheimer's dementia can present a disconnection behavior, being able to read words but with "alienation of word meaning" or read and pronounce irregular spelled words without error (Nelson and O'Connell, 1978). People with aphasia or dementia can often communicate their needs by linguistic, and paralinguistic, means to get their message across. There are differences between neurolinguistics, psycholinguistics and functional communication, but all are necessary for a comprehensive and clinically meaningful assessment. 


\section{Neurolinguistic investigations}

The first domain for assessment explores the relationship of brain damage and language impairment. In the nineteenth century, the neuropathologist Paul Broca observed left frontal pathology with dysfluent aphasia and Carl Wernicke described comprehension deficit in left temporal lobe pathology. The Russian neuro-psychologist Alexander Luria described traumatic aphasia from head wounds in the Second World War (Luria, 1968). Language representation in the normal and damaged brain was investigated by electrical stimulation of exposed tissue in the 1960 s, and more recently by brain imaging, blood-flow and metabolic studies.

A neurolinguistic test battery to describe language impairment in aphasic or cognitively impaired subjects, and used by this Speech and Communication Clinic, was devised in the Brain Metabolism Unit at the University of Edinburgh (Thompson, 1983). It has 34 four variables, including orientation, comprehension, word retrieval, grammar, reading, writing, calculation, praxis and language-mediated problem-solving. It is standardized for healthy and non-medicated populations with aphasia or dementia. The battery was used to track the language variables that decline in progressive Alzheimer's dementia and then compare those variables in subjects with aphasia or associated cognitive disorders.

The neurolinguistic data provided important information about language in people with Alzheimer's dementia (Thompson, 1986). They have difficulty remembering what is said to them even as they are listening. If instructions are given within their memory span they still have difficulty understanding logico-grammatical concepts about space, time, sequence, cause and effect. Written instructions do not assist understanding of speech. Sustained attention is lost, and psycholinguistic data suggest that auditory information may not register. Word finding impairment is common because of access to, rather than loss of, vocabulary, this being a difference between naming failure in Alzheimer's dementia and Semantic dementia. The ability to be both oriented and negotiate three-dimensional space is also compromised, as is the role of language in problem-solving.

Many abilities are resistant to dementia. They include long-learned and rehearsed material, automatic responses, reading without understanding and basic identification. The most effective communication programs for the elderly use abilities that are preserved in aging including the senses, movement, long-term memories, music and singing, such as the Irish-based SONAS: a Multi-sensory Method for Activating Potential for Com- munication in Older People (Hamill and Connors, 2004).

\section{Psycholinguistic investigations}

The second domain of assessment in the clinic is that of psycholinguistic evaluation. The Psycholinguistic Assessments of Language Processing in Aphasia (PALPA; Kay et al., 1992; 1996) aim to investigate cognitive processing and communication disorders. The Speech and Communication Clinic uses PALPA as a screening test for speech, word finding and reading in order to discover how these abilities are represented and what connections exist between them. There are indications that language as a cognitive construct is more plastic and compensatory when damage is diffuse rather than circumscribed; suggesting that the dementing brain communicates differently than the dysphasic brain. Lesions to Broca's area or Wernicke's area may destroy motor speech and comprehension as symptoms of aphasia, but they do not destroy the functional ability to communicate. This concept is not new. In 1915 Hughlings Jackson had observed that, because of differences in cerebral organization, the localization of a symptom cannot be identified with the localization of a function, or "to localize the damage that destroys speech and to localize speech are two different things" (Head, 1915; see also the discussion of this in Luria, 1966).

\section{Functional linguistics}

The third domain of language assessment is functional linguistics. This is the ability to communicate regardless of the cerebral impairment and regardless of the mode used in everyday life, after the International Classification of Impairments, Disabilities and Handicaps (World Health Organization, 1980). It is observable that dysphasic individuals can often communicate their needs. Those with mild to moderate dementia can disguise their deficits from assessors, whilst those with severe dementia can register their discomfort and outrage though behaviors which act out meaning, often interpreted as being "disruptive" or "aggressive". To tap this functional ability, patients in this speech clinic provide speech samples that are transcribed and analyzed for intelligibility. They may effectively rephrase, change topic, use circumlocution, alter intonation, pause, or use any other verbal and non-verbal strategy to enhance their communication, particularly if they are, or were, working professionals with high pre-morbid verbal intelligence and a developed cognitive reserve. 
Ben Jonson, the Elizabethan playwright, said axiomatically, "Language most shows the man; speak that I may see thee". Ultimately, what we say and how we say it, and our use of non-speech behaviors such as gaze, intonation and gesture, is the imprint of our personality interacting with others. We monitor the reaction of our listeners and change our speech to suit the situation. This appropriateness is how we adapt our speech for an acceptable manner to a particular audience. It is referred to as speech "pragmatics" and is probably the most fascinating of human communication science; the manipulation of speech and body language to best convey information, and the subtle manipulation of speech for propriety.

Clinical observation of pathological language suggests that speakers with schizophrenia are less able to repair speech errors, they maintain thought disordered discourse, often unaware the listener is perplexed. People with aphasia may have to rely on the listeners' reaction to tailor broken linguistic skills and use gesture, pantomime, or intonation when meaning through speech fails. People with Wernicke's aphasia may speak in neologisms, but curiously intonation and prosody may carry meaning. People with frontal dementia have a paucity of speech that is highly referential but leads to mutism. People with temporal lobe or Semantic dementia have empty speech without nouns, and their listeners cannot follow their topic. People with Alzheimer's dementia are fluent but there is an increasing fragmentation of meaning through loss of words, loss of context and loss of cohesion. There is increasing speech repetition or palilalia. There is also a loss of auditory memory of heard conversations and comprehension failure. These behaviors can be a burden on carers and family. Loss of language brings increasing helplessness and frustration to the carers. For those with dementia, losing the verbal skills to find directions, work and organize, express needs, and ask assistance means a loss of the ability to operate in their world.

\section{Conclusions}

The value of this collaboration between a Speech and Communication Clinic and a Memory Clinic is that it bridges community care and academic expertise. To the University it brings diversity of its teaching and clinical role by accessing communityfunded resources. Therapists working in the community gain the opportunity for academic mentoring, collaborative research, and active participation in professional development. For community health centers it affords a greater awareness of the broader welfare of communicatively impaired patients. Finally, our vulnerable aging residents, who choose to grow older at home rather than in residential care, are better protected by this integrated service.

IAN Thompson, ${ }^{1,2}$ Olga Yastrubetskaya, ${ }^{2}$ Nicola Lautenschlager, ${ }^{2,3}$ David Ames ${ }^{2,4}$ AND EDMOND CHIU ${ }^{2}$

${ }^{1}$ Inner East Community Health Service, Richmond, Melbourne, Australia

${ }^{2}$ Academic Unit for Psychiatry of Old Age, University of Melbourne, St.George's Hospital, Melbourne, Australia

${ }^{3}$ School of Psychiatry and Clinical Neurosciences and WA

Centre for Health and Ageing, University of Western

Australia, Perth, Australia

${ }^{4}$ National Ageing Research Institute, Parkville, Melbourne, Australia

Email: it@unimelb.edu.au

\section{References}

Andreasen, N. C. (1979). Thought, language and communication disorders. Archives of General Psychiatry, $36,1315-1330$

Australian Taxation Office Mean Taxable Income 20062007.

Critchley, M. (1964). The neurology of psychotic speech. British Fournal of Psychiatry, 110, 353-364.

Crow, T. J. (1977). Is schizophrenia the price that Homo sapiens pays for language?, Schizophrenia Research, 28, 127-141.

Folstein, M. F., Folstein, S. E. and McHugh, P. R. (1975). "Mini-mental state": a practical method of grading the cognitive state of patients for the clinician. Fournal of Psychiatric Research, 12, 189-198.

Goh, A. et al. (2008). Respecting the Ageing Clientele: $A$ Training Program for Commercial Service Providers. Melbourne: Academic Unit for Psychiatry of Old Age, University of Melbourne.

Hamill, R. and Connors, T. (2004). Sonas APC. In M. Jones and B.L. Meissen (eds.), Care Giving in Dementia (pp. 119-137). London: Routledge.

Hasan, R. (1984). Coherence and cohesive harmony. In J. Flood (ed.), Understanding Reading Comprehension (pp. 181-219). Newark: Delaware International Reading Association.

Head, H. (1915). Hughlings Jackson on aphasia and kindred affections of speech. Brain, 38, 1-190.

Kay, J., Lesser, R. and Coltheart, M. (1992). PALPA: Psycholinguistic Assessments of Language Processing in Aphasia. Hove: Lawrence Erlbaum Associates.

Kay, J., Lesser, R. and Coltheart, M. (1996). Clinical forum. Aphasiology, 10, 159-215.

Luria, A. (1966). Higher Cortical Functions in Man. New York: Basic Books.

Luria, A. (1968). Traumatic Aphasia. The Hague: Mouton.

Morice, R. and Ingram, J. (1982). Language analysis on schizophrenia: diagnostic implications. Australian and New Zealand Fournal of Psychiatry, 16, 11-21. 
Nelson, H. and O'Connell, A. (1978). Dementia: the estimation of pre-morbid intelligence using and New Adult Reading Test. Cortex, 14, 234-244.

NICE (2006). Clinical Guideline CG42. London: National Institute for Health and Clinical Excellence.

Stevens, S. J. (1985). The language of dementia: a pilot study. British fournal of Disorders of Communication, 20, 181190.

Thomas, P. (1997). The Dialectics of Schizophrenia. London: Free Association Books.

Thomas, P. and Fraser, W. (1994). Linguistics, human communication and psychiatry. British fournal of Psychiatry, 125, 585-592.

Thompson, I. M. (1983). BMU Language Scales (MRC Edinburgh). Bulletin, 378, 1-4. London: Royal College of Speech Therapists.
Thompson, I. M. (1986). Language pathology in Alzheimer type dementia and associated disorders. Unpublished $\mathrm{PhD}$ thesis, University of Edinburgh.

Thompson, I. M. (1987). Language in dementia. International fournal of Geriatric Psychiatry, 2, 145-161.

Thompson, I.M. and Copolov, D. (1998). The psycholinguistics of auditory hallucinations. Aphasiology, 12, 919-932.

Walker, S. A. (1982). An investigation of the communication of elderly subjects. Unpublished M.Phil. thesis, University of Sheffield.

Williamson, J. et al. (1964). Old People at home: their unreported needs. Lancet, i, 1117-1120.

World Health Organization (1980). International Classification of Impairments, Disabilities, and Handicaps. Geneva: World Health Organization. 